\title{
Performance of Dye-Sensitized Solar Cell Using Size- Controlled Synthesis of $\mathrm{TiO}_{2}$ Nanostructure
}

\author{
A. Talib ${ }^{1,2 *}$, M.K. Ahmad ${ }^{1.2}$, N. Ahmad ${ }^{1,2}$, N. Nafarizal ${ }^{1,2}$, F. Mohamad $^{1,2}$, \\ C.F. Soon ${ }^{1,2}$, A.B Suriani ${ }^{3}$, M.H. Mamat ${ }^{4}$, K. Murakami ${ }^{5}$, M. Shimomura ${ }^{5}$
}

${ }^{1}$ Department of Electronic Engineering, Faculty of Electrical \& Electronic

Universiti Tun Hussein Onn Malaysia, 86400, Parit Raja, Batu Pahat, Johor, MALAYSIA

${ }^{2}$ Microelectronics and Nanotechnology Shamsuddin Research Centre (MiNT-SRC),

Universiti Tun Hussein Onn Malaysia, 86400, Parit Raja, Batu Pahat, Johor, MALAYSIA

${ }^{3}$ Nanotechnology Research Centre, Department of Physic, Faculty of Science and Mathematics, Universiti Pendidikan Sultan Idris, 35900 Tanjung Malim, Perak, MALAYSIA

${ }^{4}$ Nano-Electronic Centre, Faculty of Electrical Engineering,

Universiti Teknologi Mara, 40450 Shah Alam, Selangor, MALAYSIA

${ }^{5}$ Department of Engineering, Graduate School of Integrated Science and Technology,

Shizuoka University, 432-8011 Hamamatsu, Shizuoka, JAPAN

*Corresponding Author

DOI: https://doi.org/10.30880/ijie.2020.12.02.013

Received 29 December 2019; Accepted 27 January 2020; Available online 28 February 2020

\begin{abstract}
Titanium dioxide $\left(\mathrm{TiO}_{2}\right)$ or titania shows a great interest in solar cell application due to its morphology and crystalline structure. Moreover, it is an affordable compound that could make solar cells more cost economical than traditional silicon solar cells. In this study, one-step hydrothermal method is demonstrated to synthesis rutile $\mathrm{TiO}_{2}$ nanorods and nanoflowers morphology in nanoscale dimension on different hydrothermal reaction times for Dye-sensitized solar cells application. Increasing the reaction time could influence in formation of higher crystalline rutile phase titania nanostructure before abruptly decreases as the prolong hydrothermal process carry out. The length of the nanorods produced shows increasing behaviour and the growth of nanoflowers are become denser obviously. Band gap estimation is $2.75 \mathrm{eV}$ slightly lower than bulk rutile $\mathrm{TiO}_{2}$. It shows that the growth mechanism under different reaction times has great influences on the morphologies and alignment of the nanostructure. Further, the DSSCs fabricated using 15 hours reaction time exhibited the best photovoltaic performance with highest efficiency of $3.42 \%$ and highest short-circuit photocurrent of $0.7097 \mathrm{~V}$.
\end{abstract}

Keywords: titanium dioxide, hydrothermal, $\mathrm{TiO}_{2}$, nanorods/nanoflowers, reaction time, DSSCs

\section{Introduction}

Titanium dioxide $\left(\mathrm{TiO}_{2}\right)$ exists in three major types in our nature that is rutile, anatase and brookite. Each polymorph has a unique phase structure known as tetragonal crystalline phase owned by anatase and rutile, whereas orthorhombic phase is belonging to brookite. Every phase of $\mathrm{TiO}_{2}$ possesses various band gap which is $3.0 \mathrm{eV}$ (rutile), $3.2 \mathrm{eV}$ (anatase) and $3.3 \mathrm{eV}$ (brookite) (Khaki et al., 2017). Rutile is well-known as the most steady phase compared to anatase and 
brookite at high temperatures, which are meta-stable at all temperatures (Mathpal et al., 2013). $\mathrm{TiO}_{2}$ can be used as photocatalyst (Addamo et al., 2008; Venkatachalam et al., 2007), water splitting, superhydrophilicity in self-cleaning glass and anti-fogging coating (Huang et al., 2017), removing airborne pollutants and wastewater treatment (Tayade $e t$ al., 2007), gas sensors (Radeva et al., 2006), Li-ion batteries materials (Yang et al., 2012), and conversion solar energy to the electricity development (Zhao et al., 2007; Kontos et al., 2008).

The morphology of $\mathrm{TiO}_{2}$ is an important feature in many uses because there are a lot of main chemical and physical occasions occur on the surface. Accordingly, substantial numbers of researches are presently fixated on the manageable synthesis of $\mathrm{TiO}_{2}$ with diverse morphologies and different sizes of particle. To date, a variety of preparation procedures have been established for the synthesis of $\mathrm{TiO}_{2}$, such as sol-gel process (Maheswari \& Venkatachalam, 2015), templateassisted (Venkatesan \& Kannan, 2017), hydrothermal (Ahmad et al., 2016), chemical bath deposition (Dhandayuthapani et al., 2016), spray pyrolysis (Oja et al., 2004) and anodization (Nishanthi et al., 2014; Sennik et al., 2014). Among them, the hydrothermal process is very facile, convenient and controllable method to fabricate $\mathrm{TiO}_{2}$ in this research.

Basically, DSSCs comprise a photoanode (the widely used $\mathrm{TiO}_{2}$ ), dye-molecules (N-719), a photocathode (Platinum), and an electrolyte solution with contains iodide (I), which can generate iodide/triiodide ( $\left.\mathrm{I}^{-} / \mathrm{I}^{3-}\right)$ ion redox pairs during illumination. Recently, lots of researchers have focused their efforts in enhancing the power conversion efficiency (PCE) of DSSCs by manipulating the photoanode with different structures (Low et al., 2018). Hence, many scholars have made endeavors to improve the transportation of electron for the improvement of the photovoltaic performance of DSSCs by controlling the structure and composition of the titania photoanode.

$\mathrm{TiO}_{2}$ nanostructures have been synthesized via different methods and evaluated. Nanosheet (Lara et al., 2018), nanowall (Daneshvar e Asl et al., 2019), nanorod (Daneshvar e Asl et al., 2019), nano/micro-sphere (Daneshvar e Asl et al., 2019; Zaki et al., 2018), nanotube (Zaki et al., 2018), nanotree (Fang et al., 2017), skeleton structure (Dong et al., 2003), microsponge (Lu et al., 2011), nanoworm (Hou et al., 2014), nanopillar (Gong et al., 2013), leaf-like mesostructure (Deepak et al., 2014), micropetal (Zhang et al., 2016), and nanostar (Pawar et al., 2016) are some examples of these structures (Daneshvar e Asl et al., 2019). It was identified that these nanoparticles can be controlled by the temperature of hydrothermal and the $\mathrm{TiO}_{2}$ precursor crystallization.

In this paper, one-step hydrothermal method is demonstrated to synthesis $\mathrm{TiO}_{2}$ nanorods / nanoflowers (NRs / NFs) morphology and the effect of the different reaction time has been studied and discussed. It shows that the growth mechanism under different relatively dependent parameters has significant influences on the morphologies, sizes and alignment of the structure synthesized.

\section{Materials and Methods}

\subsection{Preparation of $\mathrm{TiO}_{2} \mathrm{NRs} / \mathrm{NFs}$}

All the chemicals were methodical grade and tested deprived of advance purification. Fluorine doped Tin Oxide (FTO) glass $(7 \Omega / \mathrm{sq})$ with a thickness of $2.0 \mathrm{~mm}$ was cut into the pieces of $1.5 \times 2.5 \mathrm{~cm}$ in dimension as substrates. These substrates were cleaned ultrasonically in acetone followed by ethanol and eventually deionized (DI) water (18.2M $\Omega$, Mili-Q Ultrapure) for 10 minutes, respectively. In a typical synthesis, $80 \mathrm{~mL}$ deionized water and $80 \mathrm{~mL}$ concentrated hydrochloric acid ( $\mathrm{HCl})(36.5 \%-38.0 \%$ by weight) stirring for 5 minutes before a desired amount of TBOT was further lowered down by drop wise by means of using capillary tube and stirring for another 10 minutes.

The solution of mixture was relocated into a $300 \mathrm{ml}$ Teflon-lined stainless-steel autoclave where the FTO substrates were horizontally placed with an active side facing upward. Then the autoclave was sealed completely for hydrothermal synthesis with temperature of 150 degree Celsius $\left({ }^{\circ} \mathrm{C}\right.$ ) (Ahmad et al., 2016). The experiment was carried out for different reaction times of 5, 10, 15 and 25 hours respectively. After cooling down to ambient temperature, the substrates were extracted out, cleaned comprehensively with deionized water and permitted to dry naturally in room temperature.

\subsection{Fabrication of DSSC}

For the fabrication of DSSCs efficiency study, the arranged $\mathrm{TiO}_{2}$ photoanode with $0.25 \mathrm{~cm}^{2}$ working area was submerged for about 24 hours in $0.3 \mathrm{mM}$ of N719 dye at room temperature. The Platinum (Pt) counter electrode was arranged by sputtering technique. In order to bring together the DSSC, the electrolyte drop were arranged from 1,2dimethyl-3- propylimidazolium iodide, $1.59 \mathrm{~g}$, iodolyte AN 50,10 ml, 4-tert-butylpyridine, $10 \mathrm{ml}$, guanidine thiocyanate, $0.01 \mathrm{~g}$ and valeronitrile, $5 \mathrm{ml}$ was interleaved in between the two electrodes before braced for solar cell measurement (Fazli et al., 2017).

\subsection{Characterization Techniques}

The structure of crystal of the as-synthesized films was inspected by Bruker D8 Advance X-ray diffraction (XRD) with $\mathrm{CuK} \alpha$ radiation $(\lambda) 1.5406 \AA$ in the Bragg angle ranging from $20^{\circ}$ to $70^{\circ}$ at a skimming speed of $2^{\circ} \mathrm{min}^{-1}$ and the type of slot used was secured divergence slit. X-ray tube voltage and current were fixed at $40 \mathrm{kV}$ and $40 \mathrm{~mA}$, respectively. The morphology and microstructure of the samples were inspected by field emission scanning electron microscopy (FESEM, JOEL, JSM-7600F). The energy dispersive X-ray (EDX) spectroscopy (Oxford Instruments, X-Max 50 mm2 

detector, operating voltage of $10 \mathrm{kV}$, and working distance of $15.0 \mathrm{~mm}$ ) piloted to examine the composition analysis and the samples. The samples optical properties were evaluated using ultraviolet-visible (UV-Vis) spectrophotometry (Shimadzu Corporation, UV-1800). The resistivity of the samples was obtained by four-point probe measurement (Keithley 2400), Photovoltaic performances of the contrived DSSCs were analysed by using a computer-programmed Keithley 2420 Source Meter beneath the simulated sunlight illumination (100 mW/cm-2, AM 1.5) and a solar simulator (Oriel, 91160-100091192, Parccell Technologies) was used as a light source. Finally, the incident of photon-to-current conversion efficiency (IPCE) spectra characteristics were analyzed using Peccel PEC-S20 Action Spectrum Measurement System.

\section{Results and Discussion}

\subsection{Structural Properties}

XRD patterns of $\mathrm{TiO}_{2} \mathrm{NRs} / \mathrm{NFs}$ obtained by hydrothermal method are shown in Fig. 1. It provides the information of crystalline quality and the orientation of the nanostructure.

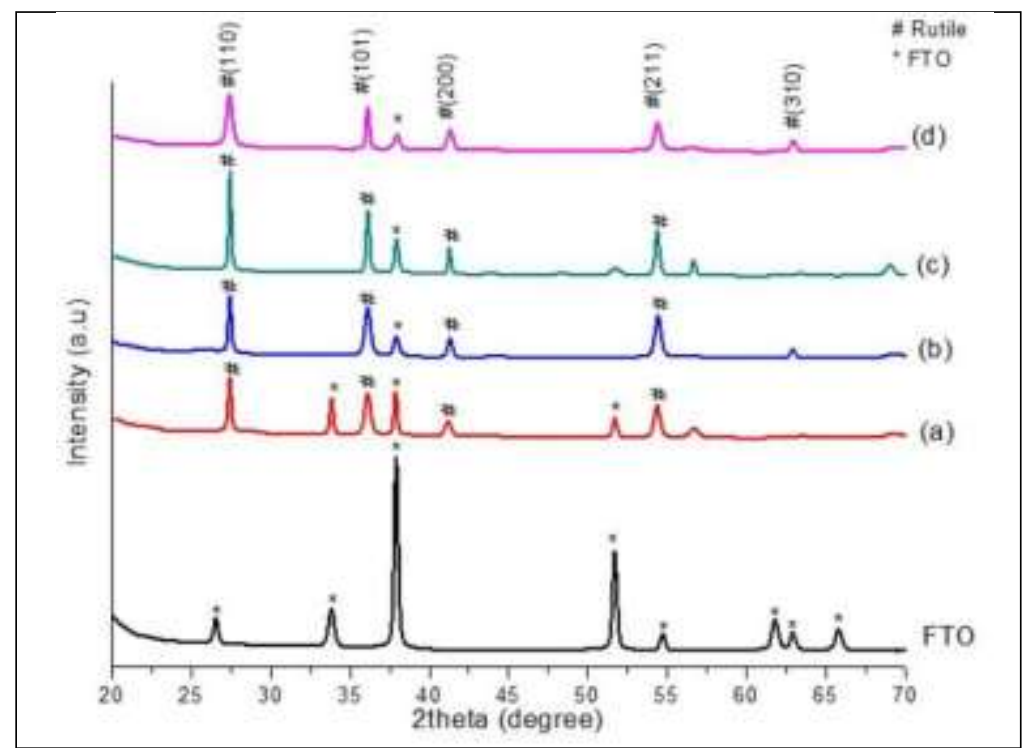

Fig. 1 - XRD patterns of the prepared samples synthesis at (a) 5; (b) 10; (c) 15; and (d) 25 hours

Table 1 - Full-width Half-Maximum and crystallite size of sample fabricated with different reaction time

\begin{tabular}{cccccc}
\hline $\begin{array}{c}\text { Reaction } \\
\text { time (h) }\end{array}$ & $\mathbf{2 \theta}\left(^{\circ}\right)$ & $\begin{array}{c}\text { Intensity } \\
(\mathbf{a . u})\end{array}$ & $\boldsymbol{\beta}$ & $\begin{array}{c}\text { Crystallite size, D } \\
(\mathbf{n m})\end{array}$ & Plane (h k I) \\
\hline 5 & 27.40 & 70 & 0.1968 & 49.52 & 110 \\
\hline 10 & 27.42 & 119 & 0.1476 & 69.27 & 110 \\
\hline 15 & 27.41 & 135 & 0.1476 & 69.27 & 110 \\
\hline 25 & 27.39 & 60 & 0.3936 & 23.73 & 110 \\
\hline
\end{tabular}

The nanostructure synthesized displayed the nature of crystalline with diffraction points lying at $2 \theta=27.5^{\circ}, 37.0^{\circ}$, $41.0^{\circ}, 54.1^{\circ}$ and $64.0^{\circ}$ can be indexed to (110), (101), (200), (211) and (310) crystal planes. The preferred orientation corresponding to the plane (110) is observed for sample synthesized at 15 hours and identified as sharpest and strongest peak. As the reaction time increase to 25 hours, a broad and lower in intensity peak could be observed suggested to a poor crystallinity of the sample. All the points in the XRD patterns can be assigned well as tetragonal rutile phase of $\mathrm{TiO}_{2}$ and the diffraction data were in good compliance with JCPDS files no. 21-1276 (Lin et al., 2014). No points corresponding to other phases of $\mathrm{TiO}_{2}$ such as anatase and brookite or any impurities were detected approving the formation of high purity and stable rutile phase of $\mathrm{TiO}_{2}$.

Crystallite size was attained by Scherrer's formula specified by equation (1): 


$$
D=\frac{\square K \lambda}{(\beta \cos \theta)}
$$

where $\mathrm{D}$ is the crystal size; $\lambda$ is the wavelength of the $\mathrm{X}$-ray radiation $(\lambda=0.15406 \mathrm{~nm})$ for $\mathrm{CuK} \alpha ; \mathrm{K}$ is constant and regularly reserved as 0.9 ; and $\beta$ is the line width at half-maximum height, and $\theta$ (theta) is half of the diffraction angle (rad) (Viswanathan \& Raj, 2009). The minimum crystallite size attained through this formula is nearly $\sim 50 \mathrm{~nm}$ at the first 5 hour and increasing dramatically to $\sim 70 \mathrm{~nm}$ in 10 hours reaction time and consistent in the next 15 hours before decreasing abruptly to $23.73 \mathrm{~nm}$ at 25 hours, respectively due to maximum peak broadening which in turn indicates its rapid size reduction when the hydrothermal reaction time is take place more than 15 hours as shown in Table 1 . This result indicated that crystal structure sizes of the resulting rutile increased with increasing the reaction growth time and consistent for a few hours before the growth is started to decrease as the equilibrium states is achieved for the samples were carried out for more than 15 hours. This result is consistent with the results of the XRD pattern that has been discussed. The crystallite size increases when time increases as increasing time allowing greater coalescence of the particles (Mokhtar et al., 2018).

\subsection{Morphological Properties}

. The morphology of nanostructured $\mathrm{TiO}_{2}$ grown on the FTO and their cross-sectional area were observed using FESEM including the thickness of the structure as shown in Fig. 2. The NRs have grown uniformly and the NFs distributed randomly occupy on several FTO surface. As the time elevated, the growth of both nanostructures becomes increases, more pack and denser and almost occupied the whole of substrate the surface. The size variation of NRs and $\mathrm{NFs} \mathrm{TiO}_{2}$ prepared by manipulating hydrothermal synthesis duration is depicted in Table 2.

Table 2 - The size of $\mathrm{TiO}_{2}$

\begin{tabular}{ccc}
\hline $\begin{array}{c}\text { Reaction time } \\
(\mathbf{h})\end{array}$ & $\begin{array}{c}\text { Length of nanorods } \\
(\mathbf{n m})\end{array}$ & $\begin{array}{c}\text { Total length } \\
(\mathbf{n m})\end{array}$ \\
\hline 5 & 1,650 & 5,140 \\
\hline 10 & 2,883 & 9,280 \\
\hline 15 & 3,150 & 14,950 \\
\hline 25 & 5,720 & 20,600 \\
\hline
\end{tabular}

Observation under FE-SEM shows images of cross-sectional area are composed of well-align NRs arrays grown on the active surface of FTO substrate decorated by NFs on the top of it under various reaction times ranging from 5 to 25 hour. The nucleation has just begun at more than 3 hours hydrothermal synthesis and 5 hours synthesis is chosen because it is an enough time to growth the double-layered structure (Liu \& Aydil, 2009). This double-layered structure combination believes are very beneficial in providing the conductive path for electron and increasing the light scattering for better light harvesting for 1D and 3D layer respectively (Shalini et al., 2018).

The influence of atom arrangement at the conductive side on the substrate and the precursor are significantly affected to the epitaxial and anisotropic nucleation and their growth mechanism (Y. Jiang et al., 2014). FTO active side is consisted of crystal tetragonal structure layer with space group $P 4_{2} / \mathrm{mnm}$; JCPDS file no: $77-0452$, $a=b=0.47538 \mathrm{~nm}, \mathrm{c}=0.3186 \mathrm{~nm}$ while $\mathrm{TiO}_{2}$ also has a crystalline tetragonal structure belong to space group P42/mnm; JCPDS No.75-1750, $\mathrm{a}=\mathrm{b}=0.45937 \mathrm{~nm}$ and $\mathrm{c}=0.29587 \mathrm{~nm}$ (Jithin et al., 2017). A similar crystal structure with small lattice mismatch around $2 \%$ would favour the epitaxial nucleation and rutile $\mathrm{TiO}_{2}$ nanostructure growth on FTO substrate (Burungale et al., 2016).

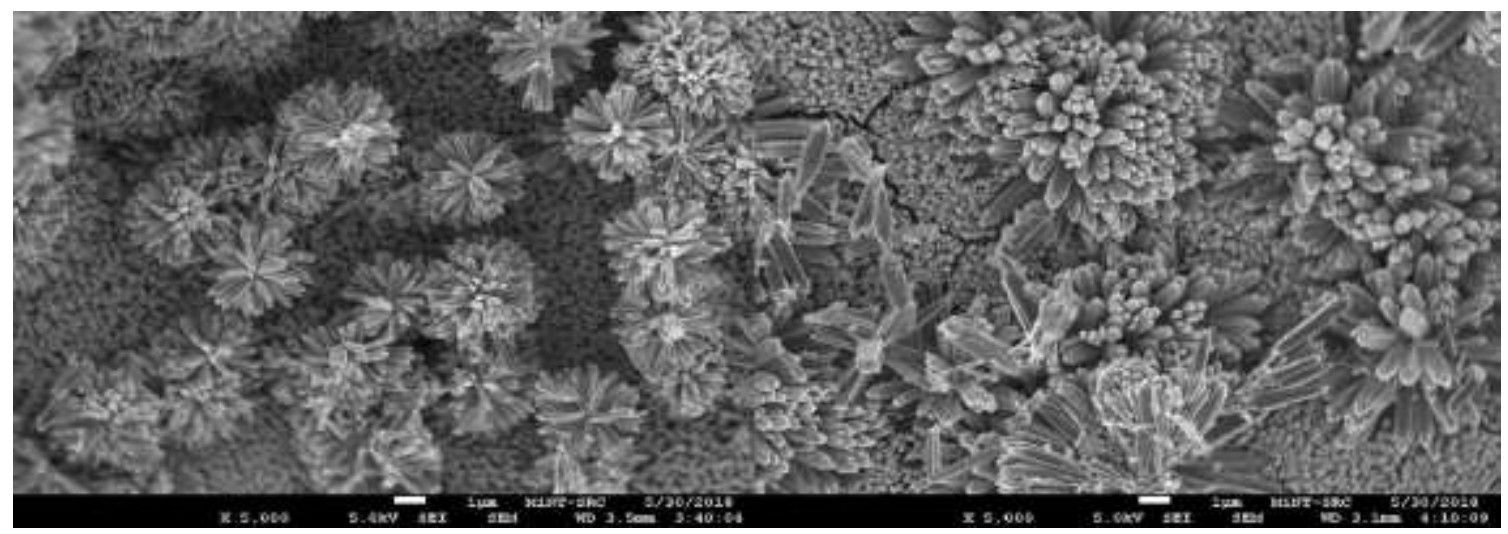

(a)

(b) 


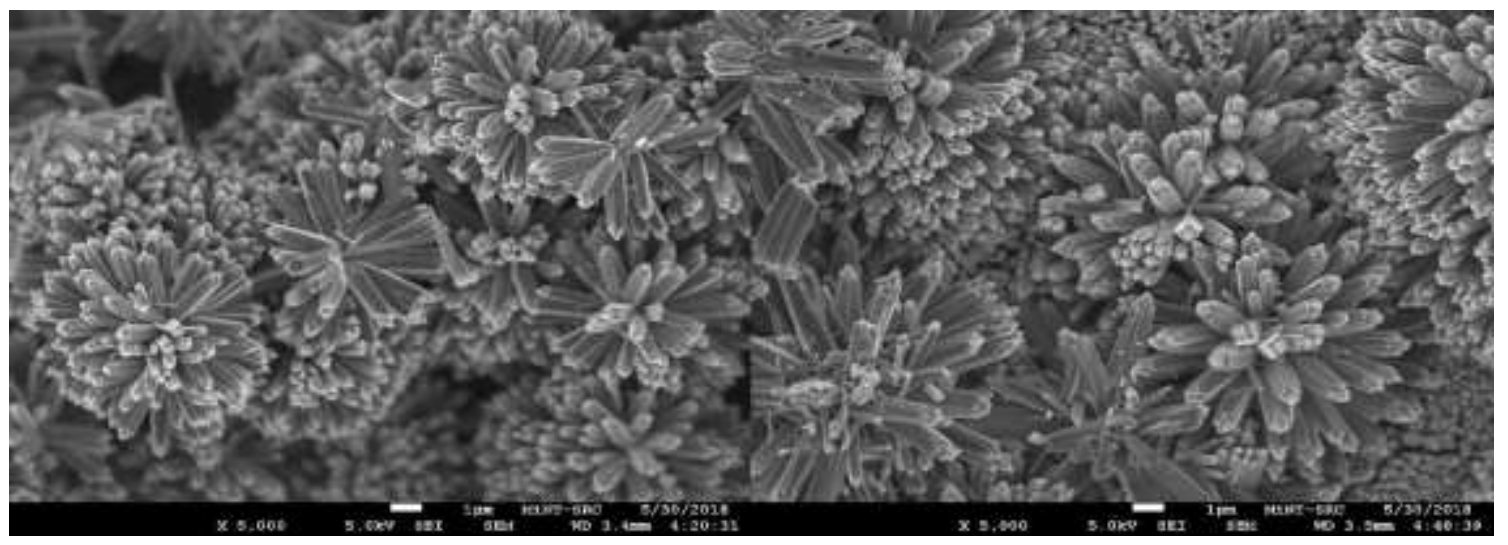

(c)

(d)

Fig. 2 - FE-SEM images of $\mathrm{TiO}_{2}$ structure synthesized at different reaction time (a) 5; (b) 10; (c) 15; (d) 25 hours

The EDX analysis has been demonstrated to determine the element composition in each of the sample and simplified in Table 3. Prolonging the synthesis time to 25 hours increased the weight percentage of Ti element composition from $37.06 \%$ for 5 hours, $39.44 \%$ for 19 hours, $40.80 \%$ for 15 hours and $45.50 \%$ for 25 hours. While having decreased in the O element composition from $62.94 \%$ for 5 hours, $60.34 \%$ for 10 hours, $59.20 \%$ for 15 hours and $54.60 \%$ for 25 hours. Therefore, it can be suggested that Ti element is increased while $\mathrm{O}$ element is decreased as the hydrothermal duration took place in prolonged time. These results are in accordance with previous literature related to the synthesis of NRs/NFs $\mathrm{TiO}_{2}$ structure at various reaction times (Ahmad et al., 2016).

Tabel 3 - EDX data for samples prepared at different reaction

\begin{tabular}{ccc}
\hline \multirow{2}{*}{$\begin{array}{c}\text { Reaction } \\
\text { time (h) }\end{array}$} & \multicolumn{2}{c}{ Element $(\mathbf{W}=$ weight\% $\mathbf{A}=$ atomic\% $)$} \\
\cline { 2 - 3 } 5 & $\mathrm{O}$ & $\mathbf{T i}$ \\
\hline \multirow{2}{*}{10} & $\mathrm{~W}=62.94$ & $\mathrm{~W}=37.06$ \\
& $\mathrm{~A}=36.19$ & $\mathrm{~A}=63.81$ \\
\hline \multirow{2}{*}{15} & $\mathrm{~W}=60.34$ & $\mathrm{~W}=39.44$ \\
& $\mathrm{~A}=33.69$ & $\mathrm{~A}=66.31$ \\
\hline \multirow{2}{*}{25} & $\mathrm{~W}=59.20$ & $\mathrm{~W}=40.80$ \\
& $\mathrm{~A}=31.46$ & $\mathrm{~A}=68.54$ \\
\hline & $\mathrm{W}=54.60$ & $\mathrm{~W}=45.40$ \\
& $\mathrm{~A}=28.66$ & $\mathrm{~A}=71.34$ \\
\hline
\end{tabular}

\subsection{Optical Properties}

Fig. 3 (a) illustrates the UV-Vis diffuse reflectance spectrum of the $\mathrm{NRs} / \mathrm{NFs}^{\mathrm{TiO}}{ }_{2}$ structure. The absorption band edges were expected around $400 \mathrm{~nm}$ slightly higher than normally reported of $\lambda=388 \mathrm{~nm} \mathrm{TiO}$. The intercept of the tangent to the plot $(\alpha h v)^{1 / 2}$ versus $(h v)$ as depicted in Figure 3(b) gives a good approximation of the band gap energy for this indirect band gap material. The graphs show the decreasing behaviour for $\mathrm{TiO}_{2}$ band gap nanostructures as the reaction time increasing. The band gap energies $\left(\mathrm{E}_{\mathrm{g}}\right)$ of as-prepared $\mathrm{TiO}_{2}$ film of 15 hours are around $2.7 \mathrm{eV}$ which are smaller than the value of $3.0 \mathrm{eV}$ for the bulk rutile $\mathrm{TiO}_{2}$ (Khaki et al., 2017).

The band gap increases with decreasing particle size and the absorption edge is shifted to a higher energy with decreasing particle size. The band gap values validate the crystallite size results according to which smaller crystallite size due to shorter reaction time should have larger band gap and large crystallite size should have smaller band gap when increasing the hydrothermally growth time of nanostructures. However, Jiang et al. claimed that the reduced band gap can be attributed to the surface oxygen deficiencies which resulted from the low temperature treatment (N. Jiang et al., 2019).

\subsection{Electrical Properties}

The current-voltage (I-V) analysis was carried out to measure the electrical properties of the $\mathrm{TiO}_{2}$ thin film by using four-point probe and the resistivity of the samples were obtained by the equation:

$$
R_{s}=\frac{\varrho}{t}
$$


where $R_{s}$ is sheet resistance, $\rho$ is resistivity and $t$ are the thickness of the growth film and the result are depicted in Table 4. The resistivity of the $\mathrm{TiO}_{2} \mathrm{NRs} / \mathrm{NFs}$ bi-layer structure is greatly dependent to the thickness of the thin film prepared. The thickness of $\mathrm{TiO}_{2} \mathrm{NRs} / \mathrm{NFs}$ increases when hydrothermal process duration carried out in an elongated time thus create the high barrier to the electron simultaneously reduced the conductivity of the samples.

The DSSCs efficiency of the $\mathrm{TiO}_{2}$ films is identified from the characteristics of photocurrent-voltage displayed in Fig. 4 under a virtual sunlight at $100 \mathrm{~mW} / \mathrm{cm}^{2}$. The information of the performances of the DSSCs was precised in Table 5 for rutile phased $\mathrm{TiO}_{2}$ photoanode.

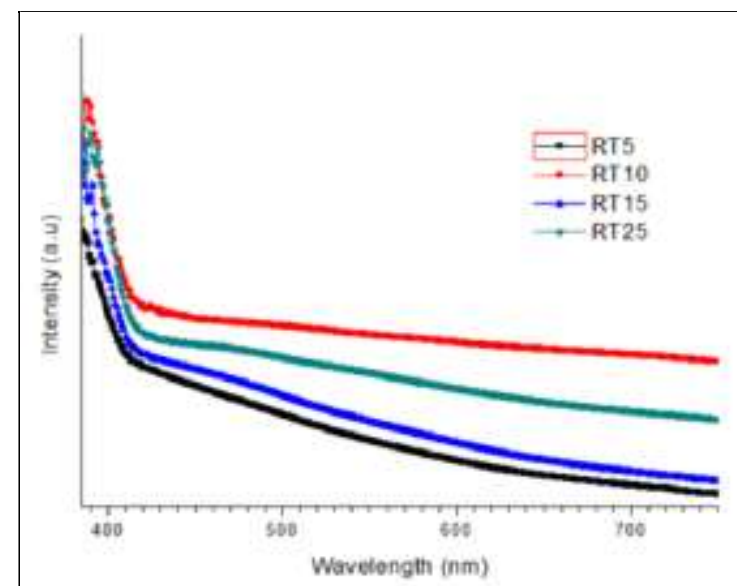

(a)

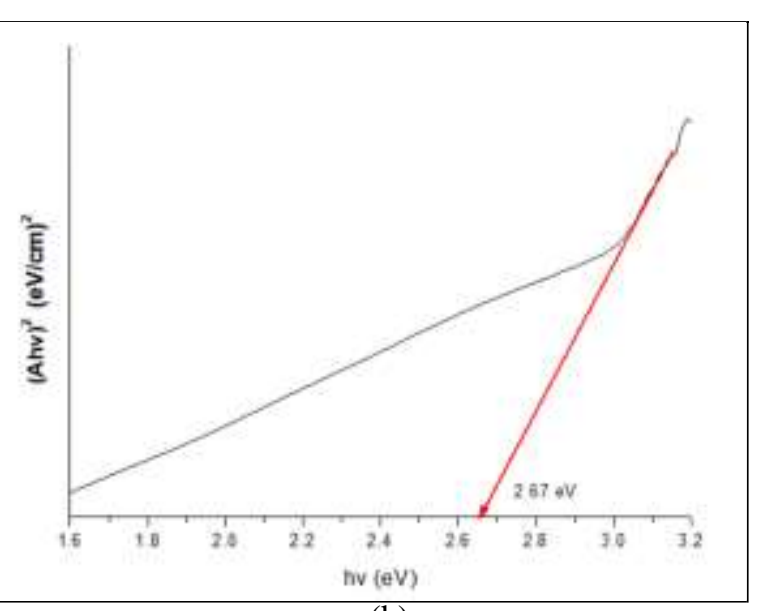

(b)

Fig. 3 - (a) UV-Vis absorbance spectrum for 5, 10, 15 and 25 hours; (b) band gap estimation for sample synthesis at 15 hours

Table 4 - Electrical properties of the sample under various reaction

\begin{tabular}{cccc}
\hline Reaction time (h) & $\begin{array}{c}\text { Sheet resistance, } \\
\mathbf{R}_{\mathbf{s}}\left(\mathbf{x} \mathbf{1 0} \mathbf{\Omega}_{\mathbf{c}} \mathbf{c m}^{\mathbf{2}}\right)\end{array}$ & $\begin{array}{c}\text { Resistivity, } \\
\boldsymbol{\rho}(\mathbf{\Omega}-\mathbf{c m})\end{array}$ & $\begin{array}{c}\text { Thickness of } \mathbf{T i O}_{\mathbf{2}} \\
\text { film (um) }\end{array}$ \\
\hline 5 & 4.23 & 3.98 & 5.14 \\
\hline 10 & 8.93 & 8.74 & 9.28 \\
\hline 15 & 5.05 & 16.8 & 14.95 \\
\hline 25 & 3.07 & 19.7 & 20.6 \\
\hline
\end{tabular}

Table 5 - Photovoltaic parameters of DSSCs with different $\mathrm{TiO}_{2}$ reaction time

\begin{tabular}{ccccc}
\hline Reaction time $(\mathbf{h})$ & Voc $(\mathrm{V})$ & $\begin{array}{c}\text { Jsc } \\
(\mathrm{mA} / \mathrm{cm} 2)\end{array}$ & $\begin{array}{c}\text { Fill Factor } \\
(\text { FF })\end{array}$ & $\begin{array}{l}\text { Efficiency } \\
\%(\eta)\end{array}$ \\
\hline 5 & $\mathbf{0 . 6 8 9 1}$ & 5.6090 & 53.79 & 2.08 \\
\hline 10 & 0.6867 & 6.3039 & 58.35 & 2.53 \\
\hline 15 & 0.7097 & 8.2310 & 58.62 & 3.42 \\
\hline 25 & 0.6915 & 8.1199 & 53.17 & 2.91 \\
\hline
\end{tabular}

The current density (Jsc) of the rutile photoanode enlarged with the reaction times along with the conversion efficiency $(\eta)$. The highest conversion efficiency of 3.42\% was given by the sample with 15 hours reaction time. A rise in the current density is the core reason for the growing in DSSCs efficiency. The current generated is identified by the number of photoelectrons from the dye molecules. Higher amount of dye molecules adsorbed onto the $\mathrm{TiO}_{2}$ obviously will create more photoelectrons. 


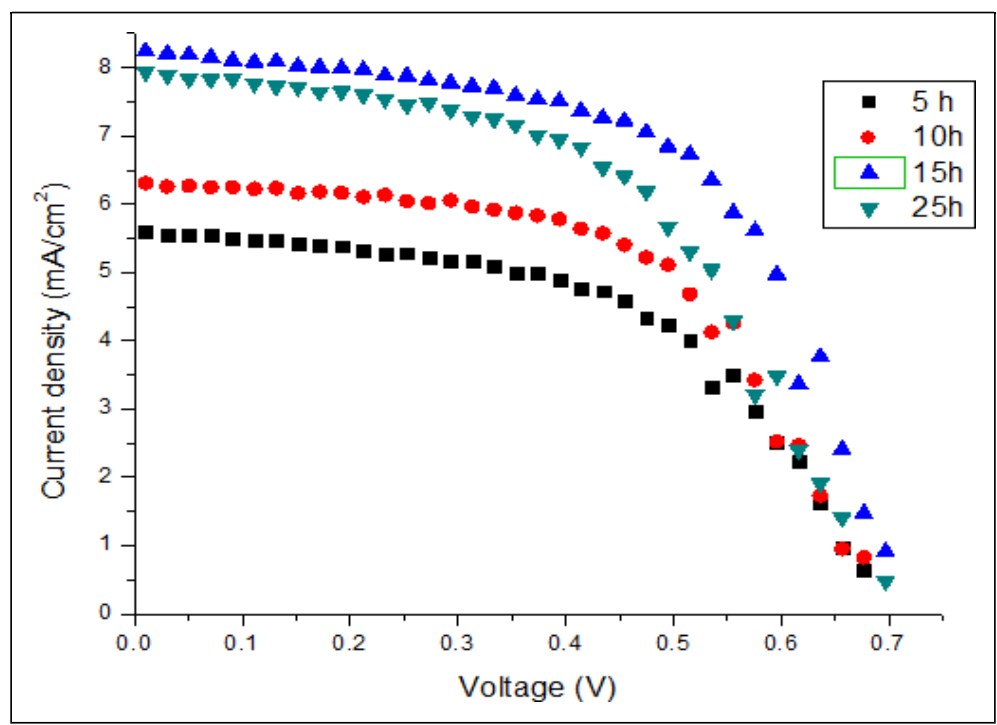

Fig. 4 - J-V characteristics of the DSSCs made with $\mathrm{TiO}_{2}$ photoanodes of different reaction time

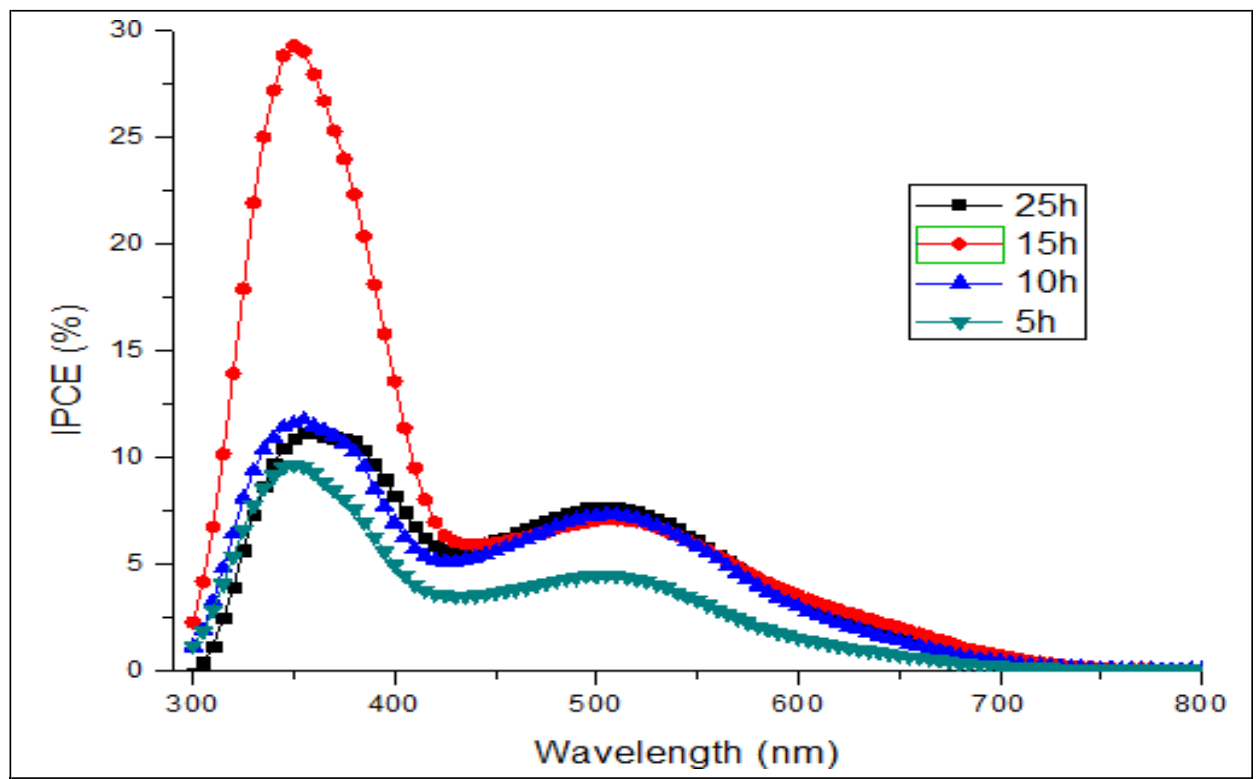

Fig. 5 - The IPCE spectra of DSSCs made with $\mathrm{TiO}_{2}$ films of different reaction time

The amount of dye molecules adsorbed onto the $\mathrm{TiO}_{2}$ can be determined by the surface area and the height of the NRs and NFs of the $\mathrm{TiO}_{2}$ samples. The enhancement of DSSCs efficiency from $2.08 \%$ to $3.42 \%$ when the $\mathrm{TiO}_{2}$ hydrothermal reaction times increased is further established by IPCE measurements characterization shown in Figure 5. The variation of IPCE values with different $\mathrm{TiO}_{2}$ reaction times also trails the similar development as the efficiency variation. All the maximum IPCE highest values are in the wavelength array from around 300 to $420 \mathrm{~nm}$. The extreme IPCE peak value of $29.31 \%$ parallels to the $\mathrm{DSSC}$ with the $\mathrm{TiO}_{2}$ reaction times of 15 hours. The rise in photon-to-current conversion efficiency up to this specific reaction time is manifestly connected to the rise in injection current from agitated dyes to the conduction band of $\mathrm{TiO}_{2}$. As the utmost photon-to-current conversion efficiency parallels to the 15 hours reaction time, the maximum rate of photon absorption by the dye and the maximum rate of electron injection from the dye to the conduction band of $\mathrm{TiO}_{2}$ obviously happen at this optimal point.

\section{Conclusion}

$\mathrm{TiO}_{2}$ thin films were successfully synthesized through one-step hydrothermal method on the FTO substrate. The growth of the rod-like structure layer is derived by tetragonal structure with small lattice mismatch. By means of parameters dependent modification, the morphological, sizes and alignment of the structure could be easily controlled. This is confirmed by FESEM images that reveal the presence of the NRs/NFs structure layer that could be tuned by dependent parameters. Band gap estimation is $2.75 \mathrm{eV}$ slightly lower than bulk rutile $\mathrm{TiO}_{2}$. It shows that the growth mechanism under different reaction times has great influences on the morphologies and alignment of the nanostructure. 
Further, the DSSCs fabricated using 15 hours reaction time exhibited the best photovoltaic performance with highest efficiency of $3.42 \%$ and highest short-circuit photocurrent of $0.7097 \mathrm{~V}$.

\section{Acknowledgement}

This research was supported by Program Hadiah Latihan Persekutuan 2017/2018, funded by Ministry of Higher Education Malaysia, Microelectronic and Nanotechnology - Shamsuddin Research Centre (MiNT-SRC) and Universiti Tun Hussein Onn Malaysia (UTHM) for the facilities and chemicals provided as well the colleagues and expertise from technical support team.

\section{References}

[1] Addamo, M., Augugliaro, V., Di Paola, A., García-López, E., Loddo, V., Marcì, G., \& Palmisano, L. (2008). Photocatalytic thin films of $\mathrm{TiO} 2$ formed by a sol-gel process using titanium tetraisopropoxide as the precursor. Thin Solid Films, 516(12), 3802-3807.

[2] Ahmad, M. K., Mokhtar, S. M., Soon, C. F., Nafarizal, N., Suriani, A. B., Mohamed, A., ... Murakami, K. (2016). Raman investigation of rutile-phased $\mathrm{TiO} 2$ nanorods/nanoflowers with various reaction times using one step hydrothermal method. Journal of Materials Science: Materials in Electronics, 27(8), 7920-7926.

[3] Ahmad, M. K., Soon, C. F., Nafarizal, N., Suriani, A. B., Mohamed, A., Mamat, M. H., ... Murakami, K. (2016). Effect of heat treatment to the rutile-based dye sensitized solar cell. Optik, 127(8), 4076-4079.

[4] Burungale, V. V., Satale, V. V., More, A. J., Sharma, K. K. K., Kamble, A. S., Kim, J. H., \& Patil, P. S. (2016). Studies on effect of temperature on synthesis of hierarchical TiO2 nanostructures by surfactant free single step hydrothermal route and its photoelectrochemical characterizations. Journal of Colloid and Interface Science, 470, 108-116.

[5] Daneshvar e Asl, S., Eslami Saed, A., \& Sadrnezhaad, S. K. (2019). Hierarchical rutile/anatase TiO 2 nanorod/nanoflower thin film: Synthesis and characterizations. Materials Science in Semiconductor Processing, 93(November 2018), 252-259.

[6] Deepak, T. G., Anjusree, G. S., Pai, K. R. N., Subash, D., Nair, S. V., \& Nair, A. S. (2014). Cabbage leaf-shaped two-dimensional TiO 2 mesostructures for efficient dye-sensitized solar cells. RSC Adv., 4(51), 27084-27090.

[7] Dhandayuthapani, T., Sivakumar, R., \& Ilangovan, R. (2016). Growth of micro flower rutile TiO2 films by chemical bath deposition technique: Study on the properties of structural, surface morphological, vibrational, optical and compositional. Surfaces and Interfaces, 4, 59-68.

[8] Dong, W., Bongard, H. J., \& Marlow, F. (2003). New type of inverse opals: Titania with skeleton structure. Chemistry of Materials, 15(2), 568-574.

[9] Fang, L., Wang, X., Wang, Z., Gong, Z., Jin, L., Li, J., ... Sun, Z. (2017). Heterostructured TiO2 nanotree arrays with silver quantum dots loading for enhanced photoelectrochemical properties. Journal of Alloys and Compounds, 730(5 January 2018), 110-118.

[10] Fazli, F. I. M., Ahmad, M. K., Soon, C. F., Nafarizal, N., Suriani, A. B., Mohamed, A., ... Murakami, K. (2017). Dye-sensitized solar Cell using pure anatase TiO2 annealed at different temperatures. Optik, 140, 1063-1068.

[11] Gong, Y. M., He, Y. X., Guo, J., \& Zhang, H. (2013). A Concise Route to Fabricate TiO2 Nanoporous and Nanopillar Films Based on Block Copolymer Self-Assembly. Advanced Materials Research, 774-776, 931-934.

[12] Hou, X., Wang, C., Zhu, W., Wang, X., Li, Y., Wang, J., ... Zhou, F. (2014). Preparation of nitrogen-doped anatase TiO 2 nanoworm / nanotube hierarchical structures and its photocatalytic effect. 29, 29-35.

[13] Huang, L., Jing, S., Zhuo, O., Meng, X., \& Wang, X. (2017). Surface Hydrophilicity and Antifungal Properties of TiO 2 Films Coated on a Co-Cr Substrate. Hindawi BioMed Research Interntional, 2017.

[14] Jiang, N., Du, Y., Liu, S., Du, M., Feng, Y., \& Liu, Y. (2019). Facile preparation of flake-like blue TiO 2 nanorod arrays for efficient visible light photocatalyst. Ceramics International, (January), 1-7.

[15] Jiang, Y., Li, M., Song, D., Li, X., \& Yu, Y. (2014). A novel 3D structure composed of strings of hierarchical $\mathrm{TiO} 2$ spheres formed on TiO2nanobelts with high photocatalytic properties. Journal of Solid-State Chemistry, 211, 90-94.

[16] Jithin, M., Saravanakumar, K., Ganesan, V., Reddy, V. R., Razad, P. M., Patidar, M. M., ... Mahalakshmi, K. (2017). Growth, mechanism and properties of TiO2nanorods embedded nanopillar: Evidence of lattice orientation effect. Superlattices and Microstructures, 109, 145-153.

[17] Khaki, M. R. D., Shafeeyan, M. S., Raman, A. A. A., \& Daud, W. M. A. W. (2017). Application of doped photocatalysts for organic pollutant degradation - A review. Journal of Environmental Management, 198, 78-94.

[18] Kontos, A. I., Kontos, A. G., Tsoukleris, D. S., Bernard, M. C., Spyrellis, N., \& Falaras, P. (2008). Nanostructured TiO2 films for DSSCS prepared by combining doctor-blade and sol-gel techniques. Journal of Materials Processing Technology, 196(1-3), 243-248. 
[19] Lara, M. A., Sayagués, M. J., Navío, J. A., \& Hidalgo, M. C. (2018). A facile shape-controlled synthesis of highly photoactive fluorine containing $\mathrm{TiO} 2$ nanosheets with high $\{001\}$ facet exposure. Journal of Materials Science, 53(1), 435-446.

[20] Lin, J., Heo, Y. U., Nattestad, A., Sun, Z., Wang, L., Kim, J. H., \& Dou, S. X. (2014). 3D hierarchical rutile TiO2 and metal-free organic sensitizer producing dye-sensitized solar cells $8.6 \%$ conversion efficiency. Scientific Reports, 4, 1-8.

[21] Liu, B., \& Aydil, E. S. (2009). Growth of oriented single-crystalline rutile TiO 2 nanorods on transparent conducting substrates for dye-sensitized solar cells. Journal of the American Chemical Society, 131(11), 3985-3990.

[22] Low, F. W., Lai, C. W., \& Hamid, S. B. A. (2018). One-step hydrothermal synthesis of titanium dioxide decorated on reduced graphene oxide for dye-sensitised solar cells application. International Journal of Nanotechnology, $15(1 / 2 / 3), 78$

[23] Lu, Y. J., Mei, J., Dong, W. J., Fu, J. L., \& Li, C. R. (2011). Synthesis of Silver-Modified Sponge-Like Titanium Dioxide Arrays with Biomimetic Structure and its Enhanced Photocatalytic. Applied Mechanics and Materials, 117-119, 824-828.

[24] Maheswari, D., \& Venkatachalam, P. (2015). Enhancing the performance of dye-sensitized solar cells based on organic dye sensitized $\mathrm{TiO} 2$ nanoparticles/nanowires composite photoanodes with ionic liquid electrolyte. Measurement, 60, 146-154.

[25] Mathpal, M. C., Tripathi, A. K., Singh, M. K., Gairola, S. P., Pandey, S. N., \& Agarwal, A. (2013). Effect of annealing temperature on Raman spectra of TiO2 nanoparticles. Chemical Physics Letters, 555, 182-186.

[26] Mokhtar, S. M., Ahmad, M. K., Soon, C. F., Nafarizal, N., Faridah, A. B., Suriani, A. B., ... Murakami, K. (2018). Fabrication and characterization of rutile-phased titanium dioxide ( $\mathrm{TiO} 2)$ nanorods array with various reaction times using one step hydrothermal method. Optik, 154, 510-515.

[27] Nishanthi, S. T., Iyyapushpam, S., Sundarakannan, B., Subramanian, E., \& Pathinettam Padiyan, D. (2014). Interrelationship between extent of anatase crystalline phase and photocatalytic activity of TiO2 nanotubes prepared by anodization and annealing method. Separation and Purification Technology, 131, 102-107.

[28] Oja, I., Mere, A., Krunks, M., Solterbeck, C.-H., \& Es-Souni, M. (2004). Properties of TiO2 Films Prepared by the Spray Pyrolysis Method. Solid State Phenomena, 99-100, 259-264.

[29] Pawar, U. T., Pawar, S. A., Jin-Hyeok, K., \& Patil, P. S. (2016). Dye sensitized solar cells based on hydrothermally grown $\mathrm{TiO} 2$ nanostars over nanorods. Ceramics International.

[30] Radeva, E. I., Martev, I. N., Dechev, D. A., Ivanov, N., Tsaneva, V. N., \& Barber, Z. H. (2006). Sensitivity to humidity of TiO2thin films obtained by reactive magnetron sputtering. Surface and Coatings Technology, 201(6), 2226-2229.

[31] Sennik, E., Kilinc, N., \& Ozturk, Z. Z. (2014). Electrical and VOC sensing properties of anatase and rutile TiO2nanotubes. Journal of Alloys and Compounds, 616, 89-96.

[32] Shalini, S., Prabavathy, N., Balasundaraprabhu, R., Kumar, T. S., Velauthapillai, D., Balraju, P., \& Prasanna, S. (2018). Studies on DSSC encompassing flower shaped assembly of Na-doped TiO2nanorods sensitized with extract from petals of Kigelia Africana. Optik, 155, 334-343.

[33] Tayade, R. J., Surolia, P. K., Kulkarni, R. G., \& Jasra, R. V. (2007). Photocatalytic degradation of dyes and organic contaminants in water using nanocrystalline anatase and rutile TiO2. Science and Technology of Advanced Materials, 8(6), 455-462.

[34] Venkatachalam, N., Palanichamy, M., \& Murugesan, V. (2007). Sol-gel preparation and characterization of nanosize TiO2: Its photocatalytic performance. Materials Chemistry and Physics, 104(2-3), 454-459.

[35] Venkatesan, A., \& Kannan, E. S. (2017). Highly ordered copper oxide (Cu 2 O) nanopillar arrays using template assisted electrodeposition technique and their temperature dependent electrical characteristics. Current Applied Physics, 17(5), 806-812.

[36] Viswanathan, B., \& Raj, K. J. A. (2009). Effect of surface area, pore volume and particle size of P25 titania on the phase transformation of anatase to rutile. Indian Journal of Chemistry - Section A Inorganic, Physical, Theoretical and Analytical Chemistry, 48(10), 1378-1382.

[37] Yang, M. C., Lee, Y. Y., Xu, B., Powers, K., \& Meng, Y. S. (2012). TiO2 flakes as anode materials for Li-ionbatteries. Journal of Power Sources, 207, 166-172.

[38] Zaki, A. H., El-Shafey, A., Moatmed, S. M., Abdelhay, R. A., Rashdan, E. F., Saleh, R. M., ... El-dek, S. I. (2018). Morphology transformation from titanate nanotubes to $\mathrm{TiO} 2$ microspheres. Materials Science in Semiconductor Processing, 75(September 2017), 10-17.

[39] Zhang, Y., Foster, C. W., Banks, C. E., Shao, L., Hou, H., Zou, G., ... Ji, X. (2016). Graphene-Rich Wrapped PetalLike Rutile TiO 2 tuned by Carbon Dots for High-Performance Sodium Storage. Advanced Materials, 28(42), 93919399.

[40] Zhao, Y., Li, C., Liu, X., \& Gu, F. (2007). Highly enhanced degradation of dye with well-dispersed TiO2nanoparticles under visible irradiation. Journal of Alloys and Compounds, 440(1-2), 281-286. 